\title{
PKM Pelatihan Penggunaan Aplikasi Murottal Metode Wafa Juz 30 Berbasis Android kepada Para Guru Ngaji di Desa Demung Kecamatan Besuki

\author{
Muafi $^{1}$, Hasip ${ }^{2}$, Irfan Ardiansyah ${ }^{3}$, Hasan Basori ${ }^{4}$, Herdiyanto ${ }^{5}$,
} Hidayatus Sofyan ${ }^{6}$, Husni Mubarok ${ }^{7}$, Ifdol Khulafaur Rosidi ${ }^{8}$, Ilzam Fauzi ${ }^{9}$ \\ Universitas Nurul Jadid, Teknik Informatika 1,2,3,4,5,6,7,8 \\ \{muafiumar76@unuja.ac.id ${ }^{1}$, hasip.4500@gmail.com ${ }^{2}$, basoridetail274@gmail.com ${ }^{4}$ herdiyanto@gmail.com ${ }^{5}$, sofyan007@gmail.com ${ }^{6}$, kevin.querijero@gmail.com khulafaurifdhol@gmail.com ${ }^{9}$ ilzamfauzi32@gmail.com ${ }^{10}$
}

Submission: 14/09/2021 Received: 31/12/2021 Published: 31/12/2021

Keywords: Method, Workshop
Katakunci: Pendampingan, Metode Wafa, Workshop
Abstract. Learning the Qur'an has various methods. The purpose of this study was to determine the implementation of the wafa method in learning the Qur'an using the Android-based Murotal application. The researcher chose the Ngaji teacher in Demung Village, Kec. The object of research is the Implementation of the Wafa Method in Juz 30 Learning based on Android. while the subject in this study is a teacher Ngaji in the village of Demung district. visit. The method used in collecting data is the method of observation, interviews, and documentation. The author uses data analysis techniques including data collection, data reduction, data presentation, and verification or drawing conclusions. The results of this study illustrate that the Implementation of the Wafa Method in Androidbased Juz 30 Learning to Ngaji Teachers in Demung Village, Kec. Besuki, carried out with the following learning steps: 1) Opener. This section consists of greetings and opening prayers as well as Alpha zone, 2) Core Activities. This section consists of the process of imitating classical reading and private reading and classical reading. 3) Closing..

\footnotetext{
Abstrak. Pembelajaran Al-Qur'an mempunyai metode yang bermacammacam. Tujuan penelitian ini adalah untuk mengetahui implementasi metode wafa dalam Pembelajaran Al-Qur'an dengan menggunakan aplikasi Murotal berbasis android. Peneliti memilih Guru Ngaji di Desa Demung Kec Besuki Kab. Situbondo. Adapun objek penelitian adalah Implementasi Metode Wafa dalam Pembelajaran Juz 30 berbasis Android. sedangkan subjek dalam penelitian ini adalah Guru Ngaji di Desa Demung Kec. Besuki. Cara yang digunakan dalam mengumpulkan data adalah dengan metode observasi, wawancara, dan dokumentasi. Penulis menggunakan teknik analisis data meliputi pengumpulan data, reduksi data, penyajian data, dan verifikasi atau penarikan kesimpulan.Hasil dari penelitian ini menggambarkan bahwa Implementasi Metode Wafa dalam Pembelajaran Juz 30 berbasis Android kepada Para Guru Ngaji di Desa Demung Kec. Besuki, dilakukan dengan langkah-langkah pembelajaran sebagai berikut: 1) Pembuka. Bagian ini terdiri dari salam dan doa pembuka serta Alpha zone, 2) Kegiatan Inti. Bagian ini terdiri dari proses Baca tiru klasikal dan Baca Simak Privat serta Baca Simak Klasikal. 3) Penutup.
} 


\section{Pendahuluan}

Metode pembelajaran memiliki kedudukan yang sangat strategis dalam mendukung akan keberhasilan suatu pengajaran. Penggunaan metode yang tepat dan efektif dalam proses belajar mengajar merupakan salah satu indikator tercapainya tujuan kegiatan belajar mengajar, selain itu juga guru profesional dan adanya sarana sebagai penunjangnya. Dalam penggunaan metode tentu mempertimbangkan tujuan yang ingin dicapai, selain itu juga mempertimbangkan bahan pelajaran, kondisi peserta didik, lingkungan dan kemampuan guru.

Seiring dengan perkembangan zaman ada banyak sekali inovasi metode pembelajaran yang menyajikan berbagai keunggulan masing-masing dan tentunya lebih menarik dari pada metode zaman dahulu. Dalam pembelajaran, metode adalah sesuatu yang dapat mempengaruhi tercapai atau tidaknya suatu tujuan pembelajaran. Dalam memilih metode tentu disesuaikan dengan kondisi yang meliputi peserta didik, lingkungan, sarana dan prasarana, dan lain sebagainya. Maka dari itu pendidik perlu memilih metode yang baik dan cocok digunakan agar dapat mencapai tujuan yang diinginkan.

Salah satu inovasi metode pembelajaran tahsin Al-Qur'an ialah metode wafa. Metode wafa merupakan pembelajaran Al-Qur'an dengan memaksimalkan pendekatan otak kanan yang komprehensif, integratif, mudah, dan menyenangkan.

Berdasarkan hasil observasi penulis yang telah melakukan observasi pendahuluan di Desa Demung Kec Besuki Kab. Situbondo dan memperoleh beberapa informasi tentang permasalahan yang ada antara lain ada banyak santri yang belum bisa dalam membaca Al-Qur'an sesuai kaidah tajwid, ada yang sudah mampu membaca Al-Qur'an namun dengan ala kadarnya tanpa memperhatikan makharijul huruf, fashahah, tajwid, panjang pendek bacaan, dan kelancaran serta keindahan dalam membaca.

Maka dari itu peneliti tertarik untuk melakukan pendampingan dan penelitian terkait dengan cara menggunakan aplikasi murottal metode wafa juz 30 berbasis android kepada para guru ngaji di desa demung kec. Besuki. yang diharapkan dapat menjadi acuan memilih metode untuk proses pembelajaran khususnya kepada guru ngaji pada desa demung kec. Besuki. 


\section{Metode}

Penelitian kualitatif digunakan untuk mendapatkan data deskriptif yang berupa kata-kata tertulis atau lisan, gambar, cerita dan sebagainya. Data itu berhubungan dengan proses suatu fenomena atau kejadian suatu peristiwa dari perencanaan hingga akhir. Jadi dalam penelitian ini mengharuskan peneliti untuk terjun langsung ke lapangan dalam rangka membaca, memahami, dan mempelajari proses yang terjadi, mencatat, menganalisis, menafsirkan hingga menarik suatu kesimpulan-kesimpulan. Penelitian yang dilakukan ialah pada saat proses interaksi berlangsung secara alami pada objek yang diteliti dengan melibatkan beberapa kegiatan seperti mengamati, mencatat, bertanya dan menggali kepada sumber yang ada hubungannya dengan kejadian yang terjadi. Karena pada penelitian ini data yang diperoleh adalah bersifat non statistic atau yang identik dengan angka dan bilangan. Peneliti dituntut agar bisa mengungkapkan suatu fenomena atau peristiwa di lapangan dengan memaksimalkan fungsi indrawinya. Dalam penelitian penulis berupaya menggambarkan tentang Bagaimana Implementasi Metode Wafa dalam Pembelajaran Tahsin A-IQur'an di guru ngaji pada desa demung kec. Besuki.

\section{Hasil}

Sebagaimana dijelaskan oleh Ustadz Rasuki, bahwa di desa demung kec. Besuki terdapat beberapa musholla yang mempunyai santri untuk mengaji Al-Qur'an Berikut merupakan daftar musholla dan guru ngaji Al-Qur'an yang ada di desa demung kec. Besuki tahun pelajaran 2020/2021.

Tabel. 1 Daftar Musholla yang mempunyai santri

\begin{tabular}{clcc}
\hline Musholla & \multicolumn{1}{c}{ Materi } & Santri & Guru Ngaji \\
\hline Al-Buhori & Tilawah, Tajwid, Ghorib & 30 Santri & Siti Zainab \\
\hline Nurul Hidaya & Tilawah, Tajwid, Ghorib & 25 Santri & Rasuki \\
\hline Al-Isthiqomah & Tilawah, Tajwid, Ghorib & 30 Santri & Subhan \\
\hline Nurul Ihsan & Tilawah, Tajwid, Ghorib & 20 Santri & Abdul Lathif \\
\hline Al Hidayah & Tilawah, Tajwid, Ghorib & 27 Santri & M. Ibril \\
\hline Nurul Iman & Tilawah, Tajwid, Ghorib & 20 Santri & Munthaha \\
\hline
\end{tabular}


Setelah peneliti mengumpulkan data melalui wawancara, observasi, dan dokumentasi, setelah data tersebut sudah direduksi dan dipaparkan, maka selanjutnya ialah melakukan analisis data yang bertujuan untuk memberikan penjelasan lebih lanjut tentang hasil penelitian.

Berikut ini adalah hasil dari analisis penulis terhadap implementasi metode Wafa dalam pembelajaran tahsin Al-Qur'an di desa demung kec. Besuki.

Adanya langkah penerapan pembelajaran yang diperinci dengan pembagian durasi waktu per segmen kegiatan merupakan salah satu faktor penentu akan keberhasilan guru dalam memaksimalkan waktu belajar bersama siswa. Pada metode pembelajaran wafa menggunakan metode 5P (Pembukaan, pengalaman, pengajaran, penilaian, penutup). Dari pemaparan hasil penelitian di atas penulis dapat menganalisis bahwa langkah-langkah yang diterapkan pada pembelajaran tahsin AlQur'an dengan metode wafa di Desa Demung, Kecamtan Besuki telah sesuai dengan urutan pada buku panduan metode wafa. Penulis telah melihat secara langsung pada saat wawancara dengan beberapa peserta didik yang sudah mampu mengenal, membedakan, dan melafalkan ayat Al-Qur'an dengan makhorijul huruf yang tepat dan dengan khas nada hijaznya. Pada saat proses pembelajarannya pun mereka terlihat asik, enjoy, dan menyenangkan. Dengan menerapkan standar langkah penerapan metode Wafa dalam pembelajaran tahsin AlQur'an, menurut penulis, proses pembelajaran Al-Qur'an Desa Demung, Kecamtan Besuki telah sesuai dengan panduan buku metode Wafa dan sesuai dengan yang diharapkan, untuk media mempembelajarannya menggunakan aplikasi android, adapun aplikasi yang digunakan dalam penelitian ini seperti berikut ini: 

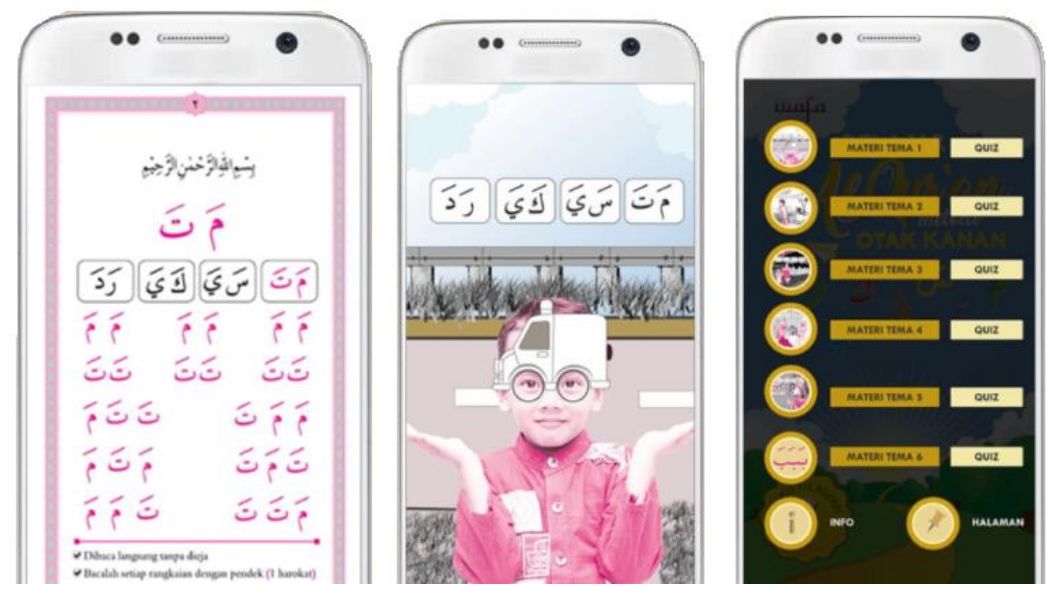

Gambar1 Aplikasi Android untuk pembelajaran

Alquran dengan metode wafa

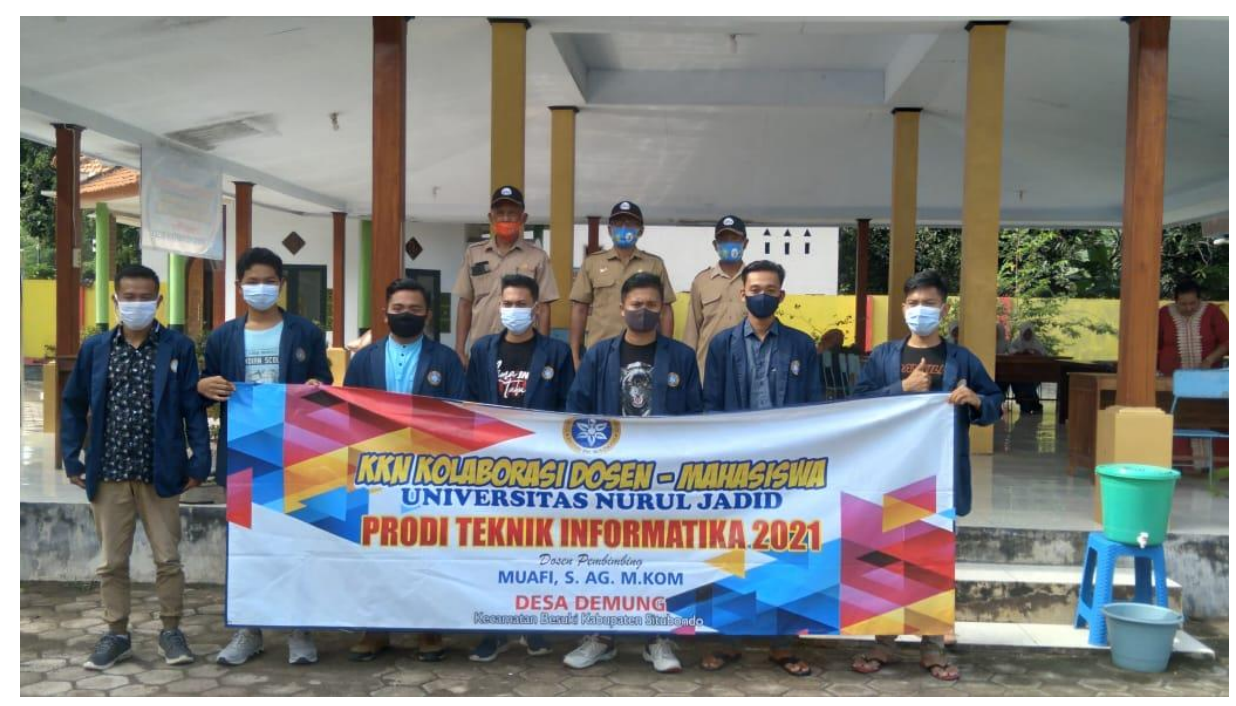

Gambar2 Foto Kegiatan KKN

\section{Pembahasan}

Kemampuan seseorang dalam memahami dan menyerap pelajaran tentu berbeda-beda. Ada yang cepat, sedang, dan ada pula lambat. Bukan hanya kecepatan yang berbeda tetapi juga cara memperoses informasi tentu berbeda pula. Cara memproses infromasi itu disebut sebagai gaya belajar.

Pengetahuan dan pemahaman terhadap modalitas belajar murid diharapkan mampu menjadi bekal bagi seorang guru dalam melakukan 
pemetaan terhadap masing-masing peserta didik. Itu dapat memudahkan guru melakukan interaksi dan komunikasi dalam kegiatan belajar mengajar. Pengetahuan dan pemahaman yang dibangun dalam modalitas belajar ini meliputi ciri tiap modalitas belajar, cara mengajar untuk tiap-tiap modalitas dan strategi yang disarankan dalam kegiatan belajar mengajar. Modalitas belajar itu sendiri merupakan cara seseorang dalam menyerap informasi lewat indra yang mereka milikinya. Cara cepat otak untuk menyerap informasi, berinteraksi dan berkomunikasi.

Modalitas belajar ini digunakan untuk memanfaatkan gaya belajar murid, karena pemanfaatan gara belajar murid yang tepat dapat mempengaruhi akan keberhasilan proses belajar murid. Pada umumnya seorang individu memiliki akses ketiga modalitas belajar mereka seperti visual, auditorial dan kinestetik, tetapi hamper semua orang cenderung memiliki modalitas belajar yang berperan sebagai penyerapan pembeljaaran, pemrosesan dan komunikasi. Orang yang tidak hanya memiliki satu modalitas belajar itulah mereka yang memiliki bakat dan kekurangan alami. Modalitas belajar terdiri dari tiga macam, yaitu visual, auditorial, dan kinestetik. Tiap-tiap modalitas belajar seseorang memiliki cirri khusus sehingga dapat digunakan sebagai pertimbangan dalam menentukan strategi dalam mengajar.

\section{Visual}

Peserta didik dalam bergaya belajar visual itu menggunakan modalitas belajar dengan kekuatan indera mata. Modalitas visual mengakses dengan cara visual yang diciptakan maupun diingat. Warna, hubungan ruang dan gambar merupakan hal yang menonjol Peserta didik dalam bergaya belajar visual itu menggunakan modalitas belajar dengan kekuatan indera mata. Modalitas visual mengakses dengan cara visual yang diciptakan maupun diingat. Warna, hubungan ruang dan gambar merupakan hal yang menonjol.

\section{Auditorial}

Peserta didik dalam bergaya belajar auditorial ini menggunakan modalitas belajar dengan kekuatan indera pendengaran yakni telinga. Modalitas belajar dengan auditorial identik dengan segala jenis bunyi dan kata. Music, nada, irama, rima, dialog internal, dan suara sangat menonjol 
dalam modalitas ini. Ciri-ciri murid yang auditorial antara lain: sering kali berbicara pada diri sendiri ketika melakukan sesuatu, mudah terganggu oleh keributan, menggerakan bibir dan mengucapkan tulisan ketika membaca, senang membaca dengan keras dan mendengarkan, dapat mengulang kembali dan menirukan nada irama, merasa kesulitan dalam menulis tetapi hebat dalam bercerita, berbicara dalam irama yang terpola dan fasih, belajar mendengarkan dan mengingat apa yang didiskusikan dari pada apa yang dilihat, suka berbicara, suka berdiskusi dan menjelaskan panjang lebar, pandai mengeja dengan keras dari pada menuliskannya, serta lebih suka gurauan lisan dari pada membaca komik. Strategi mengajar murid yang auditorial ialah sebagia berikut: a) Menggunakan variasi vokal, b) Gunakan pengulangan, minta murid menyebutkan kembali konsep kunci dan petunjuk, c) Setelah tiap pengajaran, minta murid memberitahu teman disebelahnya satu hal yang dipelajari, d) Nyanyikan konsep kunci atau meminta murid untuk mengarang lagu mengenai konpes pembelajaran, e) Dorong murid untuk memikirkan jembatan keledai untuk menghafal konsep kunci, dan f) Gunakan music sebagai aba-aba untuk memulai kegiatan rutin.

\section{Kinestetik}

Modalitas kinestetik mengakses segala jenis gerak dan emosi. Gerak, koordinasi, irama, tanggapan emosional, dan kenyamanan fisik menonjol dalam modalitas ini. Ciri-ciri murid kinestetik ini adalah menanggapi perhatian fisik, menyentuh orang untuk mendapat perhatian mereka, berdiri dekat ketika berbicara dengan orang, selalu berorientasi pada fisik dan banyak bergerak, belajar melalui manipulasi dan praktek, menghafal dengan cara berjalan dan dan melihat, menggunakan jari sebagai petunjuk ketika membaca, banyak menggunakan isyarat tubuh, tidak dapat duduk diam untuk waktu yang lama, memiliki tulisan yang jelek, ingin melakukan segala sesuatu, dan menyukai permainan yang menyibukkan.Strategi mengajar murid kinestetik antara lain: a. Gunakan alat bantu saat mengajar untuk menimbulkan rasa ingin tahu dan menekankan konsep-konsep kunci. b) Ciptakan simulasi konsep agar murid mengalaminya. c) Jika bekerja dengan murid perseorangan, berikan bimbingan parallel dnegan duduk di sebelah mereka, bukan didepan atau dibelakang murid. d) Peragakan 
konsep. sambil memberikan kesempatan kepada murid untuk mempelajarinya langkah demi langkah.

\section{Kesimpulan}

Berdasarkan pembahasan yang penuli uraikan, maka dapat diambil kesimpulan mengenai implementasi metode wafa dalam pembelajaran tahsin Al-Qur'an di Guru ngaji pada desa demung kec. Besuki yaitu bahwa Implementasi atau penerapan Metode Wafa dalam Pembelajaran Al-Qur'an di SMP IT Harapan Bunda Purwokerto telah berjalan sesuai dengan kaidah dan prinsip yang ada pada Aplikasi berbasis android dengan Metode Wafa (Wafa Tilawah1). Pembelajaran Tahsin Al-Qur'an Metode Wafa di guru ngaji pada desa demung kec. Besuki selalu memanfaatkan Aplikasi Wafa Tilawah1 serta alat pendukung seperti speaker, alat peraga, dan murottal Al-Qur'an. Dalam menjaga kualitas pembelajaran Al-Qur'an metode Wafa, guru ngaji pada desa demung kec. Besuki menyelenggarakan 4 program yang mendukung, yaitu 1) Mengikutkan Ustadz Ustadzah untuk melaksankan pelatihan Wafa agar mendapatkan sertifikasi yang menjadi salah satu kualifikasi menjadi guru Tahsin, 2) Menetapkan Model-Model Pembelajaran, 3) Menetapkan langkah-langkah penerapan pembelajaran dalam kelas, 4) Menetapkan tujuan dan target pembelajaran.

\section{Referensi}

Agil Husin Al Munawar, Said. 2002. Al-Qur'an: Membangun Tradisi Kesalehan Hakiki. Jakarta: Ciputat Press.

A'yun Via Nurrahma,Qurrota. "Penerapan Metode Wafa dalam eningkatkan Keberhasilan pada Program tahfidzul Qur'an Siswa Kelas 6 SDIT Nurul Fikri Sidoarjo,"Skripsi. Sidoarjo: UIN Sunan Ampel Surabaya.

Alwasilah, Chaedar. 2017. Pokoknya Kualitatif: Dasar-Dasar Merancang dan Melakukan Penelitian Kualitatif. Bandung: Dunia Pustaka Jaya.

Annuri, Achmad. 2018. Panduan Tahsin Tilawah Al-Qur'an \& Ilmu Tajwid. Jakarta: Pustaka Al-Kautsar.

Ardy Wiyani, Novan. 2010. Inovasi Kurikulum dan Pembeljaaran PAI SMA 
Berbasis Pendidikan Karakter. Yogyakarta: A-Ruzz Media.

Arifin, Zainal. 2012. Penelitian Pendidikan: Metode dan Paradigma Baru.

Bandung: Remaja Rosdakarya.

Bahri Djamarah, Syauful. 2011. Psikologi Belajar. Jakarta: Rineka Cipta.

Churmain, Muhammad. 2017."Peningkatan Kualitas Membaca Al-Qur'an secara Tartil dengan Metode Qiro'ati pada Siswa Kelas X TKR 1 SMK Ma'arif

Tegalrejo Kabupaten Magelang,”Skripsi. Magelang: IAIN Salatiga. 